\title{
BMJ
}

\section{Prolonged conservative care versus early surgery in patients with sciatica from lumbar disc herniation: cost utility analysis alongside a randomised controlled trial}

\author{
Wilbert B van den Hout, health economist, ${ }^{1}$ Wilco C Peul, neurosurgeon, ${ }^{2,3}$ Bart W Koes, professor of \\ general practice, ${ }^{4}$ Ronald Brand, statistician, ${ }^{5}$ Job Kievit, professor, ${ }^{1}$ Ralph T W M Thomeer, neurosurgeon, ${ }^{2}$ \\ for the Leiden-The Hague Spine Intervention Prognostic Study Group
}

Department of Medical Decision Making, Leiden University Medical Center, PO Box 9600, 2300

RC Leiden, Netherlands

${ }^{2}$ Department of Neurosurgery, Leiden University Medical Center ${ }^{3}$ Department of Neurosurgery, Medical Center Haaglanden, the Hague, Netherlands

${ }^{4}$ Department of General Practice, Erasmus MC, University Medical Center Rotterdam, Netherlands

${ }^{5}$ Department of Medical Statistics, Leiden University Medical Center Correspondence to: $\mathrm{W}$ B van den Hout hout@lumc.nl

doi:10.1136/bmj.39583.709074.BE

\section{ABSTRACT}

Objective To determine whether the faster recovery after early surgery for sciatica compared with prolonged conservative care is attained at reasonable costs. Design Cost utility analysis alongside a randomised controlled trial.

Setting Nine Dutch hospitals.

Participants 283 patients with sciatica for 6-12 weeks, caused by lumbar disc herniation.

Interventions Six months of prolonged conservative care compared with early surgery.

Main outcome measures Quality adjusted life years (QALYS) at one year and societal costs, estimated from patient reported utilities (UK and US EuroQol, SF-6D, and visual analogue scale) and diaries on costs (healthcare, patient's costs, and productivity).

Results Compared with prolonged conservative care, early surgery provided faster recovery, with a gain in QALYS according to the UK EuroQol of 0.044 (95\% confidence interval 0.005 to 0.083 ), the US EuroQol of 0.032 ( 0.005 to 0.059 ), the SF-6D of 0.024 (0.003 to 0.046$)$, and the visual analogue scale of $0.032(-0.003$ to 0.066$)$. From the healthcare perspective, early surgery resulted in higher costs (difference $€ 1819$ ( $£ 1449 ;$ 2832), 95\% confidence interval $€ 842$ to $€ 2790$ ), with a cost utility ratio per QALY of $€ 41000$ ( $€ 14000$ to $€ 430000$ ). From the societal perspective, savings on productivity costs led to a negligible total difference in cost $(€-12, €-4029$ to $€$ €4006).

Conclusions Faster recovery from sciatica makes early surgery likely to be cost effective compared with prolonged conservative care. The estimated difference in healthcare costs was acceptable and was compensated for by the difference in absenteeism from work. For a willingness to pay of $€ 40000$ or more per QALY, early surgery need not be withheld for economic reasons. Trial registration Current Controlled Trials ISRCTN 26872154.

\section{INTRODUCTION}

As the clinical course of sciatica is favourable, international consensus has been that surgery should be offered only if symptoms persist after a period of conservative treatment. ${ }^{1}$ The optimal timing of disc surgery has not been scientifically established..$^{2-5}$ In a randomised controlled trial we compared the effectiveness of early surgery for sciatica with six months of prolonged conservative care ${ }^{6-8}$ The trial showed faster recovery after early surgery, but without any difference after a year.

Early surgery is associated with higher short term healthcare costs than prolonged conservative care. Several economic evaluations have compared surgical procedures $^{9-12}$ or non-surgical types of care. ${ }^{13-16}$ The two economic evaluations that compared surgery with conservative care suggested favourable cost effectiveness for surgery, but used either extensive modelling ${ }^{17}$ or a case-control design. ${ }^{18}$ As a result the cost effectiveness of early surgery for sciatica is yet to be established. ${ }^{19}$ We carried out a cost utility analysis of our randomised controlled trial, comparing observed quality adjusted life years (QALYs) at one year with observed societal costs at one year, to determine whether the faster recovery after early surgery is attained at reasonable costs.

\section{METHODS}

Patients participated in a multicentre randomised controlled trial that compared six months of prolonged conservative care for sciatica with early surgery. ${ }^{6}$ Participants gave written informed consent.

A total sample size of 280 was chosen, sufficient to detect a three point difference on the Roland disability questionnaire for sciatica. ${ }^{20}$ Between November 2002 and February 2005, 283 patients were enrolled. The early surgery group and prolonged conservative care group showed no clinically or statistically significant differences at baseline (table 1). ${ }^{78}$

\section{Patients and treatment}

Eligible patients were aged 18 to 65 years, with a radiologically confirmed disc herniation and lumbosacral radicular syndrome that had lasted for six to 12 weeks. We excluded patients presenting with cauda 
equina syndrome, muscle paralysis, or insufficient strength to move against gravity. Other exclusion criteria were another episode of symptoms similar to those of the current episode during the previous 12 months, previous spine surgery, bony stenosis, spondylolisthesis, pregnancy, or severe coexisting disease.

The details of treatment can be found elsewhere. ${ }^{6}$ Briefly, early surgery was scheduled within two weeks after randomisation and cancelled only if spontaneous recovery occurred before the date of surgery. The disc herniation was removed through a unilateral transflaval approach using magnification. Prolonged conservative care was provided by the general practitioner. If sciatica persisted at six months after randomisation, microdiscectomy was offered. Increasing leg pain not responsive to drugs and progressive neurological deficit were reasons for performing surgery earlier than six months. Patients were advised to resume their regular jobs when they were able, depending on the nature of their work.

\section{Utilities and QALYS}

Utilities represent the valuation of the quality of life of the patients, on a scale from zero (as bad as death) to one (perfect health). Patients described their quality of life using the EuroQol classification system (EQ-5D), ${ }^{21}$

Table 1|Baseline characteristics of patients randomised to receive early surgery for sciatica or prolonged conservative care. Values are numbers (percentages) of patients unless stated otherwise

\begin{tabular}{|c|c|c|}
\hline Variable & $\begin{array}{c}\text { Prolonged } \\
\text { conservative care } \\
(n=142)\end{array}$ & Early surgery $(n=141)$ \\
\hline Mean (SD) age (years) & $43(10)$ & $42(10)$ \\
\hline Men & $97(68)$ & $89(63)$ \\
\hline Mean (SD) Quetelet's index & $26(4)$ & $26(4)$ \\
\hline Mean (SD) duration of sciatica (weeks) & $9.5(2.1)$ & $9.4(2.4)$ \\
\hline Absenteeism from work & $116(82)$ & $107(76)$ \\
\hline Positive straight leg raising test* & $104(73)$ & $100(71)$ \\
\hline Positive crossed straight leg raising test* & $70(49)$ & $71(50)$ \\
\hline Sensory loss & $128(90)$ & $123(87)$ \\
\hline Dermatome anaesthesia & $33(23)$ & $31(22)$ \\
\hline Muscle weakness & $99(70)$ & $93(66)$ \\
\hline Knee tendon reflex difference & $51(36)$ & $54(38)$ \\
\hline Ankle tendon reflex difference & $107(75)$ & $75(53)$ \\
\hline Mean (SD) finger to ground distance $(\mathrm{cm})$ & $35(17)$ & $33(16)$ \\
\hline \multicolumn{3}{|c|}{ Mean (SD) patient reported visual analogue scales: } \\
\hline Leg pain† & $64(21)$ & $67(28)$ \\
\hline Back pain† & $31(28)$ & $34(30)$ \\
\hline Leg and back pain $†$ & $58(20)$ & $61(22)$ \\
\hline General health $\ddagger$ & $46(25)$ & $47(25)$ \\
\hline Roland disability score§ & $16(4)$ & $17(4)$ \\
\hline
\end{tabular}

*Lasègue's sign was defined positive if examiner observed a typically dermatomal area of pain reproduction and pelvic muscle resistance below a unilateral 60 degree angle provocative straight leg raising, and crossed positive ifit was noted on raising other leg below 90 degrees.

†Intensity of pain indicated on $100 \mathrm{~mm}$ visual analogue scale, with 0 representing no pain and 100 worst pain ever experienced.

$\ddagger$ General health indicated on $100 \mathrm{~mm}$ visual analogue scale, with 0 representing worst imaginable health and 100 best imaginable health.

§Roland disability questionnaire for sciatica measures functional status in patients with pain in leg or back. Scores range from 0 to 23 , with higher scores indicating worse functional status. from which we calculated utilities for the United Kingdom and United States. ${ }^{2223}$ Similarly, patients reported their quality of life using the SF-36, from which we calculated the SF-6D utilities. ${ }^{24}$ Both EQ-5D and SF-6D provide societal valuation, which is preferred for economic evaluations from a societal perspective. Although less appropriate for the societal perspective, we also obtained valuations by the patients themselves, using a visual analogue scale ranging from 0 (worst imaginable health) to 100 (perfect health). We transformed the values to a utility scale, ${ }^{25}$ using the power transformation 1-(1-visual analogue scale/ $100)^{1.61}$

We obtained measurements for EQ-5D and the visual analogue scale at $-2,0,2,4,8,12,26,38$, and 52 weeks after randomisation. SF-36 measurements were obtained less often, at $-2,8,26$, and 52 weeks after randomisation. For the EQ-5D, SF-36, and visual analogue scale measurements, $4 \%, 5 \%$, and $5 \%$ of the items were missing, respectively, and we imputed these using the rounded average within the same randomisation group at the same time. From the area under the utility curves we calculated the average utility during each separate quarter of the year after randomisation and during the entire year (QALYs).

\section{Costs}

We estimated the costs from the societal perspective during the one year of follow-up. Because of the one year time horizon, costs were not discounted. Costs were converted to price levels in March 2008 using the general Dutch consumer price index. ${ }^{26}$

Using cost diaries, patients reported admissions to hospital, visits (specialists, general practitioner, physical therapy, paramedical professionals, and alternative health care), homecare, paid domestic help, informal care, drugs and aids (for example, crutches), out of pocket expenses as a result of the hernia (for example, swimming), and hours of absenteeism from work Diaries were scheduled to be handed in at 2, 4, 8, 12, 26, 38 , and 52 weeks after randomisation. The $26(9 \%)$ patients who did not return cost diaries were equally distributed over both randomisation groups $(\mathrm{P}=0.98)$ and were less likely to have undergone surgery $(\mathrm{P}<0.001)$. We corrected for selective non-response by multiple imputing data on costs from patients who did return cost diaries (from the same randomisation group and with the same surgical status),${ }^{27}$ and this did not substantially change the results compared with excluding these patients. For patients who did return cost diaries, the diaries covered $97 \%, 91 \%, 83 \%$, and $84 \%$ of the first to fourth quarters. For periods that were not covered by a cost questionnaire we imputed with the closest available diary from the same patient.

In the Dutch funding system, individual hospitals set diagnosis-treatment prices for disc surgery to facilitate competition and price containment. From the prices available for 75 different centres, we excluded the two highest and two lowest prices. The remaining prices ranged from $€ 3421$ (£2726; \$5327) to $€ 4935$, with an average of $€ 4002$. To introduce a cost structure 
dependent on the duration of hospital stay, we converted the average price to $€ 2357$ per admission to hospital plus $€ 390$ per bed day. ${ }^{2829}$ With an average hospital stay of 3.7 days, and adding the costs of related specialist visits, this rendered average costs per hospital stay equal to the average diagnosis-treatment price.

For other health care we used Dutch standard prices, designed to represent societal costs and to standardise economic evaluations. ${ }^{28-31}$ Costs from the healthcare perspective are reported, including the patients' time ${ }^{31}$ and travel costs, ${ }^{28}$ which on average accounted for $17 \%$ of the total healthcare costs. We valued the reported hours of absenteeism from work during the one year follow-up period according to the human capital method, at standard costs ranging from $€ 17$ per hour for 18 year old women to $€ 41$ per hour for 65 year old men. ${ }^{28}$

\section{Analysis}

According to protocol the base case cost utility analysis compared societal costs at one year to QALYs at one year based on the UK EQ-5D. Because of the limited degree of modelling in this cost utility analysis, we carried out sensitivity analyses only on the use of different utility measures (UK EQ-5D, US EQ-5D, SF$6 \mathrm{D}$, or visual analogue scale) and on the included cost categories (societal or healthcare perspective).

Depending on the willingness to pay for obtained effectiveness, a strategy is cost effective compared with an alternative strategy if it has a better average net benefit (willingness to pay $\times$ QALYs - costs). Given the statistical uncertainty of differences between costs and QALYs, cost effectiveness acceptability curves graph the probability that a strategy is cost effective, as a function of willingness to pay. We calculated confidence intervals for cost utility ratios as those willingness to pay values for which the difference in net benefit was not statistically significantly different. ${ }^{32}$ To facilitate multiple imputation techniques we statistically analysed group differences using standard $t$ tests for unequal variance. All analyses followed the intention to treat principle.

\section{RESULT}

\section{Utilities and QALYS}

According to the EQ-5D, the valuation of quality of life two weeks after randomisation for early surgery for sciatica was worse than for prolonged conservative care (fig 1). Other than that, the utility measures were almost consistently better after early surgery than after prolonged conservative care. The largest difference in utilities was 0.123 (95\% confidence interval 0.061 to 0.185), according to the UK EQ-5D, eight weeks after randomisation.

QALYs during all four quarters and according to all four utility measures were consistently more favourable after early surgery (table 2). Both the first and the second quarter showed statistically significant differences on all four utility measures. Likewise, over the first year early surgery provided significantly better QALYs (UK and US EQ-5D and SF-6D) or marginally

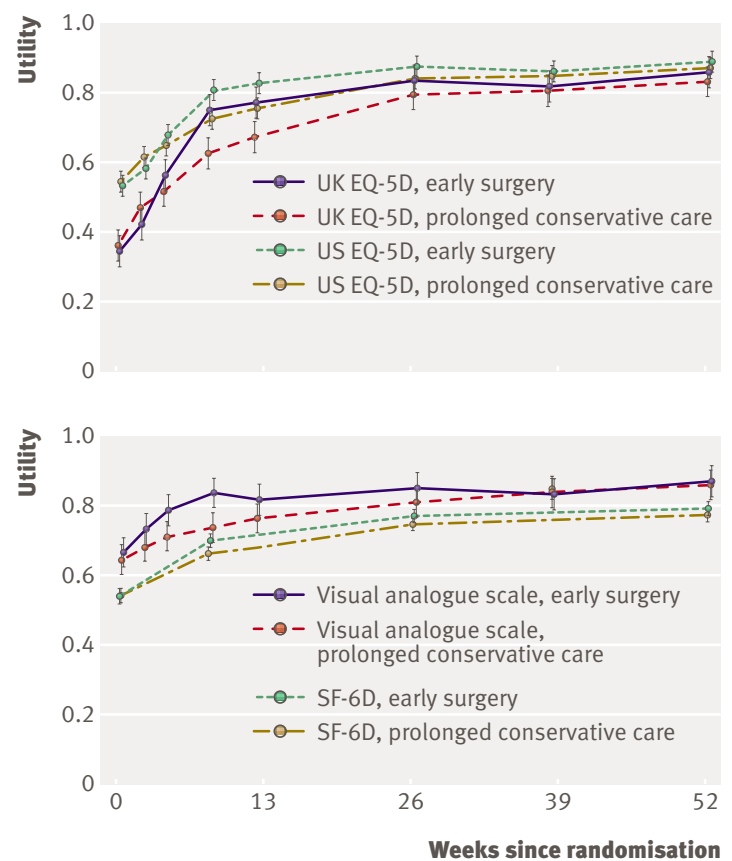

Fig 1| Utilities according to UK and US EQ-5D, SF-6D, and visual analogue scale

significantly better QALYs (visual analogue scale). The difference in QALYs according to the UK EQ-5D was 0.044 (95\% confidence interval 0.005 to 0.083$)$, for the US EQ-5D was 0.032 (0.005 to 0.059$)$, the SF-6D was $0.024(0.003$ to 0.046$)$, and the visual analogue scale was $0.032(-0.003$ to 0.066$)$.

\section{Healthcare costs}

Of the patients randomised to receive early surgery, $89 \%$ received disc surgery during the first year compared with $40 \%$ of the patients randomised to receive prolonged conservative care (table 3). Overall, $4 \%$ and $1 \%$, respectively, had recurrent sciatica leading to a second surgical intervention during the first year. The difference in disc surgery resulted in a cost difference of $€ 2127$ (95\% confidence interval $€ 1345$ to $€ 2908$ ).

The higher costs of surgery after early surgery were partly compensated for by statistically significant savings on visits to a general practitioner, physical therapy in the third quarter, and analgesics. Even so, over the first year, total healthcare costs after early surgery remained significantly higher than prolonged conservative care, with a difference in costs of $€ 1819$ (€842 to $€ 2790)$ per patient.

\section{Societal costs}

Of the non-healthcare costs, the use of informal care after early surgery was significantly higher than after prolonged conservative care. Also, productivity costs were higher in the first quarter but were lower in later quarters (significant in the second and third quarters). The total difference in absenteeism from work per patient was 39 ( -67 to 144 ) hours in favour of early surgery, with an associated difference in productivity 
Table 2 | Utility and quality of life years (QALYs) after early surgery for sciatica or prolonged conservative care. Values are means (standard deviations) unless stated otherwise

\begin{tabular}{|c|c|c|c|c|}
\hline Variable & $\begin{array}{l}\text { Prolonged conservative } \\
\text { care }(n=142)\end{array}$ & $\begin{array}{l}\text { Early surgery } \\
\qquad(n=141)\end{array}$ & Difference & Pvalue* \\
\hline \multicolumn{5}{|l|}{ UK EQ-5D: } \\
\hline 1st quarter & $0.57(0.22)$ & $0.63(0.18)$ & 0.062 & 0.01 \\
\hline 2nd quarter & $0.74(0.20)$ & $0.81(0.21)$ & 0.067 & 0.006 \\
\hline 3rd quarter & $0.80(0.18)$ & $0.83(0.21)$ & 0.025 & 0.28 \\
\hline 4th quarter & $0.82(0.19)$ & $0.84(0.18)$ & 0.021 & 0.35 \\
\hline QALYS & $0.73(0.16)$ & $0.78(0.17)$ & 0.044 & 0.03 \\
\hline \multicolumn{5}{|l|}{ US EQ-5D: } \\
\hline 1st quarter & $0.69(0.15)$ & $0.73(0.13)$ & 0.042 & 0.01 \\
\hline 2nd quarter & $0.80(0.14)$ & $0.85(0.14)$ & 0.049 & 0.003 \\
\hline 3rd quarter & $0.85(0.13)$ & $0.87(0.15)$ & 0.021 & 0.20 \\
\hline 4th quarter & $0.86(0.14)$ & $0.88(0.13)$ & 0.015 & 0.34 \\
\hline QALYS & $0.80(0.11)$ & $0.83(0.12)$ & 0.032 & 0.02 \\
\hline \multicolumn{5}{|l|}{ SF-6D: } \\
\hline 1st quarter & $0.63(0.10)$ & $0.66(0.10)$ & 0.030 & 0.01 \\
\hline 2nd quarter & $0.72(0.11)$ & $0.75(0.11)$ & 0.026 & 0.04 \\
\hline 3rd quarter & $0.75(0.13)$ & $0.77(0.12)$ & 0.020 & 0.19 \\
\hline 4th quarter & $0.77(0.12)$ & $0.79(0.13)$ & 0.020 & 0.18 \\
\hline QALYS & $0.72(0.09)$ & $0.74(0.09)$ & 0.024 & 0.03 \\
\hline \multicolumn{5}{|c|}{ Visual analogue scale: } \\
\hline 1st quarter & $0.72(0.19)$ & $0.79(0.16)$ & 0.069 & 0.001 \\
\hline 2nd quarter & $0.79(0.20)$ & $0.84(0.20)$ & 0.046 & 0.05 \\
\hline 3rd quarter & $0.83(0.20)$ & $0.84(0.20)$ & 0.012 & 0.62 \\
\hline 4th quarter & $0.85(0.19)$ & $0.85(0.18)$ & 0.000 & 0.99 \\
\hline QALYS & $0.80(0.15)$ & $0.83(0.14)$ & 0.032 & 0.07 \\
\hline
\end{tabular}

costs of $€ 2445$ (95\% confidence interval $€-1132$ to $€ 6019)$. After one year $6 \%$ of the patients who had early surgery reported being disabled, compared with $4 \%$ after prolonged conservative care (difference $2 \%,-4 \%$ to $7 \%$ ). The total non-healthcare costs after early surgery were lower than after prolonged conservative care, with a total non-significant difference of $€ 1831$ ( $€$ -1823 to $€ 5480)$. This difference was similar in size to the opposite difference in healthcare costs, resulting in a negligible difference in total societal costs of $€-12$ ( $€$ -4029 to $€ 4006$ ), slightly in favour of early surgery.

\section{Cost utility analysis}

From the societal perspective, both costs and QALYs based on the UK EQ-5D were in favour of early surgery. According to this base case analysis, early surgery is cost effective compared with prolonged conservative care, regardless of the willingness to pay per QALY. As a result of the statistical uncertainty about costs and QALYs the probability that early surgery is cost effective compared with prolonged conservative care varies with the willingness to pay (fig 2). From the societal perspective, this probability was $76 \%$ at $€ 40000$ per QALY and was $87 \%$ at $€ 80000$ per QALY.

With other utility measures (US EQ-5D, SF-6D, and visual analogue scale), both societal costs and QALYs remain in favour of early surgery, but with smaller differences in QALYs (table 2). For the US EQ-5D utility measure, the probability that early surgery is preferred reduces to $71 \%$ at $€ 40000$ per QALY and to $83 \%$ at $€ 80000$ per QALY (fig 2).

From the healthcare perspective, the higher healthcare costs would no longer be compensated for by productivity costs. As a result, the probability that early surgery is preferred is less favourable than from the societal perspective (fig 2). For the utility measures according to the UK EQ-5D and the US EQ-5D, the cost utility ratio was estimated at $€ 41000$ per QALY (95\% confidence interval $€ 14000$ to $€ 430000)$ and $€ 57000$ per QALY (€19000 to $€ 436000)$, respectively. In the Netherlands, costs are commonly classified as definitely acceptable up to $€ 20000$ per QALY, as acceptable up to $€ 40000$ per QALY, and as possibly acceptable up to $€ 80000$ per QALY. ${ }^{334}$ According to this rule, the higher healthcare costs for early surgery are classified as acceptable or possibly acceptable.

\section{DISCUSSION}

Our randomised controlled trial compared early surgery for sciatica that had lasted for six to 12 weeks with prolonged conservative care for six months. ${ }^{6}$ The trial showed faster pain relief and perceived recovery after early surgery but without any difference after a year. ${ }^{78}$ In both randomisation groups about $95 \%$ of patients reported complete or near complete resolution of symptoms. Similarly, the utility measures reported here showed a faster recovery after early surgery, with 
Table 3 | Mean healthcare costs and societal costs per patient after early surgery for sciatica or prolonged conservative care. Volumes are percentages unless stated otherwise

\begin{tabular}{|c|c|c|c|c|c|c|}
\hline \multirow[b]{2}{*}{ Variable } & \multicolumn{2}{|c|}{$\begin{array}{l}\text { Prolonged conservative care } \\
\qquad(n=142)\end{array}$} & \multicolumn{2}{|c|}{ Early surgery $(n=141)$} & \multicolumn{2}{|c|}{ Difference } \\
\hline & Volume & Costs $(€)$ & Volume & Costs $(€)$ & Costs $(€)$ & $P_{\text {value }}^{*}$ \\
\hline \multicolumn{7}{|c|}{ Disc surgery, with admission to hospital: } \\
\hline 1st quarter & 20 & 669 & 88 & 3277 & 2608 & $<0.001$ \\
\hline 2nd quarter & 13 & 620 & 2 & 316 & -304 & 0.05 \\
\hline 3rd quarter & 6 & 357 & 0 & 131 & -226 & 0.11 \\
\hline 4th quarter & 3 & 140 & 1 & 189 & 50 & 0.67 \\
\hline Total (SD) & 40 & $1786(3363)$ & 89 & $3912(3160)$ & 2127 & $<0.001$ \\
\hline \multicolumn{7}{|l|}{ Physical therapy: } \\
\hline 1st quarter & 82 & 480 & 90 & 567 & 87 & 0.15 \\
\hline 2nd quarter & 63 & 323 & 60 & 235 & -88 & 0.10 \\
\hline 3rd quarter & 52 & 260 & 46 & 143 & -118 & 0.01 \\
\hline 4th quarter & 35 & 159 & 33 & 108 & -51 & 0.24 \\
\hline Total (SD) & 89 & $1223(1420)$ & 92 & $1054(962)$ & -169 & 0.26 \\
\hline Other admissions to hospital & 4 & 63 & 1 & 11 & -52 & 0.17 \\
\hline Neurologist & $0.7 \dagger$ & 89 & $0.7 \dagger$ & 94 & 5 & 0.84 \\
\hline Neurosurgeon & $1.1 \dagger$ & 142 & $1.5 \dagger$ & 212 & 69 & 0.007 \\
\hline Other specialists & $0.2 \dagger$ & 23 & $0.5 \dagger$ & 43 & 21 & 0.17 \\
\hline General practitioner & $4.3 \dagger$ & 161 & $2.6 \dagger$ & 100 & -62 & 0.006 \\
\hline Other paramedical professionals & $0.3 \dagger$ & 18 & $0.2 \dagger$ & 14 & -5 & 0.59 \\
\hline Alternative care & $0.4 \dagger$ & 25 & $0.2 \dagger$ & 19 & -6 & 0.79 \\
\hline Home care & $4.8 \ddagger$ & 134 & $2.6 \ddagger$ & 69 & -65 & 0.53 \\
\hline Analgesics & 86 & 79 & 87 & 32 & -47 & 0.001 \\
\hline Other drugs & 22 & 11 & 32 & 13 & 2 & 0.82 \\
\hline Aids & 16 & 51 & 21 & 54 & 3 & 0.95 \\
\hline \multicolumn{7}{|l|}{ Total healthcare costs: } \\
\hline 1st quarter & & 1621 & & 4257 & 2637 & $<0.001$ \\
\hline 2nd quarter & & 1085 & & 659 & -425 & 0.02 \\
\hline 3rd quarter & & 723 & & 359 & -364 & 0.03 \\
\hline 4th quarter & & 379 & & 349 & -29 & 0.80 \\
\hline Total (SD) & & 3807 (4237) & & $5626(3875)$ & 1819 & $<0.001$ \\
\hline Paid domestic help & $1.5 \ddagger$ & 15 & $3.1 \ddagger$ & 32 & 16 & 0.26 \\
\hline Informal care & $25.2 \ddagger$ & 276 & $71.2 \ddagger$ & 781 & 505 & 0.04 \\
\hline Out of pocket expenses & 12 & 22 & 13 & 113 & 92 & 0.18 \\
\hline \multicolumn{7}{|l|}{ Productivity costs: } \\
\hline 1st quarter & $193 \ddagger$ & 6648 & $224 \ddagger$ & 7292 & 643 & 0.42 \\
\hline 2nd quarter & $117 \ddagger$ & 4082 & $76 \ddagger$ & 2268 & -1813 & 0.004 \\
\hline 3rd quarter & $67 \ddagger$ & 2325 & $46 \ddagger$ & 1355 & -970 & 0.05 \\
\hline 4th quarter & $39 \ddagger$ & 1331 & $31 \ddagger$ & 1026 & -305 & 0.50 \\
\hline Total (SD) & $416 \ddagger$ & $14385(16037)$ & $377 \ddagger$ & 11941 (12 879) & -2445 & 0.18 \\
\hline Total non-healthcare costs (SD) & & $14699(16110)$ & & $12867(13455)$ & -1831 & 0.33 \\
\hline \multicolumn{7}{|l|}{ Total societal costs: } \\
\hline 1st quarter & & 8426 & & 11980 & 3555 & $<0.001$ \\
\hline 2nd quarter & & 5237 & & 3190 & -2047 & 0.005 \\
\hline 3rd quarter & & 3109 & & 1898 & -1211 & 0.04 \\
\hline 4th quarter & & 1733 & & 1424 & -309 & 0.55 \\
\hline Total (SD) & & $18506(18$ 102) & & $18493(14548)$ & -12 & 1.00 \\
\hline
\end{tabular}

$€ 1(£ 0.8 ; \$ 1.6)$.

${ }^{*} t$ test for unequal variance, correcting for selective non-response using multiple imputation.

†Number of visits.

$\ddagger$ Number of hours.

the largest difference in utilities of 0.123 at eight weeks. The total difference in QALYs was estimated at 0.044 , which is the equivalent of a life prolongation of 16 days in perfect health.
In the economic evaluation we studied whether the faster recovery after early surgery was attained at reasonable costs. The difference in healthcare costs was estimated at $€ 1819$ and mostly consisted of the 


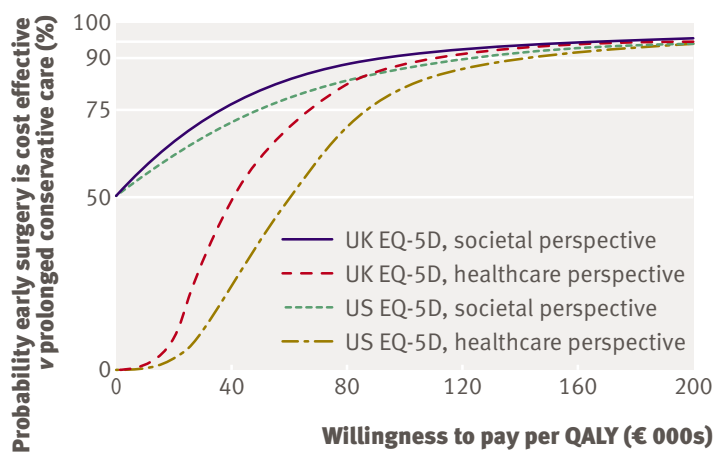

$\overline{\text { Fig } 2 \text { Cost effectiveness acceptability curves for early surgery }}$ compared with prolonged conservative care

difference in surgery costs. This difference is relatively small, because with prolonged conservative care $40 \%$ of the patients still underwent surgery as a result of increased or persistent symptoms . Partly as a result of increased absenteeism from work directly after surgery, the observed total difference in absenteeism in favour of early surgery was only 37 hours. This small difference in productivity costs was, however, sufficient to compensate for the difference in healthcare costs. As a result, from the societal perspective early surgery was preferred on both QALYs and costs. From the healthcare perspective, the cost-utility ratio was estimated at $€ 41000$ per QALY. From both perspectives, albeit with considerable uncertainty, early surgery was likely to be cost effective compared with prolonged conservative care, according to the current Dutch economic threshold of $€ 40000$ or more per QALY. ${ }^{34}$ Nevertheless, if a well informed patient prefers conservative care, there is no health economic reason to opt for early surgery, since surgery does not reduce costs and the difference in QALYs was relatively small.

Although the two earlier economic evaluations by Malter ${ }^{17}$ and Hansson ${ }^{18}$ also reported favourable costutility for disc surgery, our results differ from theirs in several ways. Firstly, our observed difference in QALYs of 0.044 is considerably smaller. On the basis of the trial by Weber, ${ }^{35}$ the Malter's trial modelled a 10 fold larger difference of 0.43 QALYs, of which 0.10 QALYs were in the first year. The control patients in the trial by Weber took longer to improve than our control patients, which is probably a result of the more common use of disc surgery in our trial. Hansson estimated a 0.327 difference in QALYs, but this estimate was based on only two measurements, after 28 days and two years, which makes it impossible to estimate the course over time. Secondly, the assumed average charge for disc surgery in Malter's trial was considerably higher than our finding (\$11930 v€4002). Yet, our price is similar to the cost estimate used by Hansson (\$4685) and to Malter's alternative health maintenance organisation costs $(\$ 5170)$, which Malter considers a better estimate of the true costs of surgery. Thirdly, in our trial the initial absenteeism from work as a result of surgery was compensated for by lower absenteeism from work during the rest of the year, whereas in Hansson's study it was compensated for by a lower incidence of permanent disability. We did not find a difference in permanent disability, which might result from the higher rate of surgery in our control group or Hansson's non-randomised case-control design.

\section{Limitations of study}

Our study has several limitations. Firstly, our Dutch setting may differ from other settings, both for health care and for employment conditions. As in the United States, surgery rates in the Netherlands are relatively high. ${ }^{2}$ In settings with lower surgery rates, patients receiving prolonged conservative care would be less likely to receive surgery, which might lead to larger differences in QALYs and costs, with an as yet unknown influence on the cost-utility ratio. Settings also differ for timing of surgery. ${ }^{5}$ In our study, early surgery was on average carried out three months after the diagnosis of sciatica. In a setting with a longer waiting period both treatment strategies would be more similar, which would reduce the differences in QALYs and costs, with unknown influence on the costutility ratio. Our patients' average hospital stay of 3 . 7 days might be relatively high, but this would affect the results only if the total costs of $€ 4002$ per admission to hospital for disc surgery would change: since other healthcare costs are comparable in both randomisation groups, the difference in healthcare costs is about proportional to the costs of hospital stay. Dutch labour legislation is relatively protective towards employees, which is likely to increase absenteeism from work but does not necessarily affect productivity.

Secondly, we limited the duration of the economic evaluation to one year because a longer time horizon would have reduced the statistical power and the clinical evaluation showed no differences beyond the first year. ${ }^{8}$ Thirdly, as patients were inevitably aware of which randomisation group they were in, their reported utilities and costs may have been influenced by their preference for treatment.

Finally, some may consider the number of crossovers in our study a limitation: $40 \%$ of the patients randomised to receive prolonged conservative care underwent disc surgery at any time during the first year. Compared with other recent randomised trials, our number of crossovers was similar to that in the trial by Österman ${ }^{36}$ and considerably less than in the trial by Weinstein. ${ }^{378}$ More importantly, we do not think that crossovers are a limitation: our analysis did not evaluate surgery itself but compared a strategy of early surgery with a strategy of prolonged conservative care. That persistent or increasing symptoms cause some patients to cross over is part of clinical reality and should therefore also be part of the economic evaluation.

In conclusion, faster recovery from sciatica of six to 12 weeks' duration caused by lumbar disc herniation makes early surgery likely to be cost effective compared with prolonged conservative care. The 


\section{WHAT IS ALREADY KNOWN ON THIS TOPIC}

Early surgery for sciatica caused by lumbar disc herniation and lasting six to 12 weeks results in faster recovery than prolonged conservative care

After a year results of both treatment strategies are similar

\section{WHAT THIS STUDY ADDS}

Early surgery provides better quality adjusted life years than prolonged conservative care

The difference in healthcare costs is acceptable and compensated for by the difference in absenteeism from work to lumbar disc herniation. A cost and quality-of-life evaluation. Pharmacoeconomics 1994;6:453-63.

10 Stevenson RC, McCabe C), Findlay AM. An economic evaluation of a clinical trial to compare automated percutaneous lumbar discectomy with microdiscectomy in the treatment of contained lumbar disc herniation. Spine 1995;20:739-42.

11 McKinley DS, Shaffer LM. Cost effectiveness evaluation of ADCON-L adhesion control gel in lumbar surgery. Neurol Res 1999;21(suppl 1):S67-71.

12 Ozkose Z, Ercan B, Unal Y, Yardim S, Kaymaz M, Dogulu F, et al. Inhalation versus total intravenous anesthesia for lumbar disc herniation: comparison of hemodynamic effects, recovery characteristics, and cost. / Neurosurg Anesthesiol 2001;13:296-302.

13 Lafuma A, Bouvenot G, Cohen C, Eschwege E, Fagnani F, Vignon E. A pragmatic cost-effectiveness study of routine epidural corticosteroid injections for lumbosciatic syndrome requiring inhospital management. Rev Rhum Engl Ed 1997;64:549-55.

14 Karppinen J, Ohinmaa A, Malmivaara A, Kurunlahti M, Kyllonen E, Pienimaki T, et al. Cost effectiveness of periradicular infiltration for sciatica: subgroup analysis of a randomized controlled trial. Spine 2001;26:2587-95

15 Ostelo RW, Goossens ME, de Vet HC, van den Brandt PA. Economic evaluation of a behavioral-graded activity program compared to physical therapy for patients following lumbar disc surgery. Spine 2004;29:615-22.

16 Price C, Arden N, Coglan L, Rogers P. Cost-effectiveness and safety of epidural steroids in the management of sciatica. Health Technol Assess 2005;9:1-58, iii.

Prognostic Study Group were-protocol committee: WCP, BWK, and RTWMT; steering committee: BWK, RTWMT, JAH Eekhof, JTJ Tans, WBvdH, WCP, RB, and HC van Houwelingen. WBvdH did the statistical analysis. He is guarantor for the paper. WBvdH, WCP, BWK, RB, and JK prepared the manuscript. The following research nurses collected and managed the data: M Nuyten, P Bergman, G Holtkamp, S Dukker, A Mast, L Smakman, C Waanders, L Polak, and A Nieborg. The participating hospitals and coordinating physicians were: Medical Center Haaglanden, The HagueJTJ Tans and R Walchenbach; Diaconessen Hospital, Leiden-J van Rossum, P Schutte, and RTWMT; Groene Hart Hospital, Gouda-G AM Verheul, JE Dalman, and JAL Wurzer; Reinier de Graaf Hospital, Delft/ Voorburg-JWA Sven and A Kloet; Spaarne Hospital, Heemstede/Haarlem -ISJ Merkies and H van Dulken; Bronovo Hospital, The Hague-PCLA Lambrechts and JAL Wurzer; Haga Hospital, The Hague-RWM Keunen and CFE Hoffmann; Rijnland Hospital, Leiderdorp/Alphen ad Rijn—J Haan and $H$ van Dulken; Lange Land Hospital, Zoetermeer-R Groen and RRF Kuiters; Leiden University Medical Center, Leiden-RAC Roos and JHC Voormolen; Public Health and Primary Care, Leiden University, LeidenAH Eekhof

Funding: Grant from the health care efficiency research programme of the Netherlands Organization for Health Research and Development. Competing interest: None declared.

Ethical approval: Medical ethics committees of the nine participating hospitals.

Provenance and peer review: Not commissioned; externally peer reviewed.

1 Andersson GB, Brown MD, Dvorak J, Herzog RJ, Kambin P, Malter A, et al. Consensus summary of the diagnosis and treatment of lumbar disc herniation. Spine 1996;21:S75-8.

2 Cherkin DC, Deyo RA, Loeser JD, Bush T, Waddell G. An international comparison of back surgery rates. Spine 1994;19:1201-6.

3 Vader JP, Porchet F, Larequi-Lauber T, Dubois RW, Burnand B. Appropriateness of surgery for sciatica: reliability of guidelines from expert panels. Spine 2000;25:1831-6.

4 Luijsterburg PA, Verhagen AP, Braak S, Avezaat CJ, Koes BW. Do neurosurgeons subscribe to the guideline lumbosacral radicular syndrome? Clin Neurol Neurosurg 2004;106:313-7.

5 Koes BW, van Tulder MW, Peul WC. Diagnosis and treatment of sciatica. BMJ 2007;334:1313-7.

6 Peul WC, van Houwelingen HC, Van den Hout WB, Brand R, Eekhof JA, Tans JT, et al. Prolonged conservative treatment or 'early' surgery in sciatica caused by a lumbar disc herniation: rationale and design of a randomized trial [ISRCT 26872154]. BMC Musculoskelet Disord 2005;6:8.

7 Peul WC, van Houwelingen HC, Van den Hout WB, Brand R, Eekhof JA, Tans IT, et al. Surgery versus prolonged conservative treatment for sciatica. N Engl J Med 2007;356:2245-56.

8 Peul WC, Van den Hout WB, Brand R, Thomeer RT, Koes BW, for the Leiden-The Hague Spine-Intervention-Prognostic-Study Group. Prolonged conservative care versus early surgery in patients with sciatica caused by lumbar disc herniation: two year results of a randomised controlled trial. BMJ 2008;10.1136/bmj.a143.

9 Launois R, Henry B, Marty JR, Gersberg M, Lassale C, Benoist M, et al. Chemonucleolysis versus surgical discectomy for sciatica secondary
17 Malter AD, Larson EB, Urban N, Deyo RA. Cost-effectiveness of lumbar discectomy for the treatment of herniated intervertebral disc. Spine 1996;21:1048-54.

18 Hansson E, Hansson T. The cost-utility of lumbar disc herniation surgery. Eur Spine J 2007;16:329-37.

19 Carragee E. Surgical treatment of lumbar disk disorders. JAMA 2006;296:2485-7.

20 Patrick DL, Deyo RA, Atlas SJ, Singer DE, Chapin A, Keller RB. Assessing health-related quality of life in patients with sciatica. Spine 1995;20:1899-908.

21 The EuroQol Group. EuroQol-a new facility for the measurement of health-related quality of life. Health Policy 1990;16:199-208.

22 Dolan P. Modeling valuations for EuroQol health states. Med Care 1997;35:1095-108.

23 Shaw JW, Johnson JA, Coons SJ. US valuation of the EQ-5D health states: development and testing of the D1 valuation model. Med Care 2005;43:203-20.

24 Brazier J, Roberts J, Deverill M. The estimation of a preference-based measure of health from the SF-36. J Health Econ 2002;21:271-92.

25 Stiggelbout AM, Eijkemans MJ, Kiebert GM, Kievit J, Leer JW, Haes HJd. The 'utility' of the visual analog scale in medical decision making and technology assessment. Is it an alternative to the time trade-off? Int J Technol Assess Health Care 1996;12:291-8.

26 Statistics Netherlands. Consumer price index. May 2008. www.cbs.

27 Briggs A, Clark T, Wolstenholme J, Clarke P. Missing ... presumed at random: cost-analysis of incomplete data. Health Econ 2003;12:377-92.

28 Oostenbrink JB, Koopmanschap MA, Rutten FFH. Manual for cost analyses, methods and standard prices for economic evaluations in health care. [In Dutch.] Amstelveen: Dutch Health Insurance Executive Board, 2004.

29 Oostenbrink JB, Koopmanschap MA, Rutten FF. Standardisation of costs: the Dutch manual for costing in economic evaluations. Pharmacoeconomics 2002;20:443-54.

30 Dutch Health Insurance Executive Board. Pharmacotherapeutic compass. [In Dutch.] August 2006. www.fk.cvz.nl.

31 Van den Berg B, Brouwer W, van ExelJ, Koopmanschap M. Economic valuation of informal care: the contingent valuation method applied to informal caregiving. Health Econ 2005;14:169-83.

32 Zethraeus N, Johannesson M, Jonsson B, Lothgren M, Tambour M. Advantages of using the net-benefit approach for analysing uncertainty in economic evaluation studies. Pharmacoeconomics 2003;21:39-48.

33 Smulders YM, Thijs A. The cost per year of life gained: trends and internal contradictions. [In Dutch.] Ned Tijdschr Geneeskd 2006;150:2467-70

34 Ubel PA, Hirth RA, Chernew ME, Fendrick AM. What is the price of life and why doesn't it increase at the rate of inflation? Arch Intern Med 2003;163:1637-41.

35 Weber $\mathrm{H}$. The effect of delayed disc surgery on muscular paresis. Acta Orthop Scand 1975;46:631-42.

36 Österman H, Seitsalo S, Karppinen J, Malmivaara A. Effectiveness of microdiscectomy for lumbar disc herniation: a randomized controlled trial with 2 years of follow-up. Spine 2006;31:2409-14.

37 Weinstein JN, Tosteson TD, Lurie JD, Tosteson AN, Hanscom B, Skinner JS, et al. Surgical vs nonoperative treatment for lumbar disk 
herniation: the spine patient outcomes research trial (SPORT): a randomized trial. JAMA 2006;296:2441-50.

38 Weinstein JN, Lurie JD, Tosteson TD, Skinner JS, Hanscom B, Tosteson AN, et al. Surgical vs nonoperative treatment for lumbar disk herniation: the spine patient outcomes research trial (SPORT) observational cohort. JAMA 2006;296:2451-9.

Accepted: 15 May 2008 